\title{
Comparison of Antioxidative Effects of Biguanides and Sulfonylureas Monotherapy on Total Antioxidant Status in Newly-Diagnosed Patients with Type 2 Diabetes Mellitus
}

\section{Siddique MAH ${ }^{1}$, Begum A², Begum S ${ }^{2}$, Khan $\mathrm{MH}^{3}$, Saiedullah $\mathbf{M}^{4 *}$, Haque $\mathrm{A}^{5}$, Rahman $\mathrm{MN}^{6}$ and Ali $\mathrm{L}^{1}$}

${ }^{1}$ Department of Biochemistry and Cell Biology, Bangladesh University of Health Sciences (BUHS), Bangladesh ${ }^{2}$ Department of Applied Laboratory Sciences, Bangladesh University of Health Sciences (BUHS), Bangladesh

${ }^{3}$ Department of Biochemistry and Molecular Biology, University of Rajshahi, Rajshahi-6205, Bangladesh

${ }^{4}$ Department of Physiology and Molecular Biology, Bangladesh University of Health Sciences (BUHS), Bangladesh

${ }^{5}$ Department of Nutrition and Food Engineering, Daffodil International University, Dhaka, Bangladesh

${ }^{6}$ Department of Biochemistry and Molecular Biology, Jahangirnagar University, Savar, Dhaka, Bangladesh

\begin{abstract}
Objective: The objective of this study was to compare total antioxidant status (TAS) in type 2 diabetic patients treated with Biguanides monotherapy and Sulfonylureas monotherapy in a tertiary health care center.

Methods: Fifty subjects using Biguanides monotherapy and another 50 subjects using Sulfonylureas monotherapy for the management of type 2 DM were included. Their fasting plasma glucose (FPG), postprandial plasma glucose (PPG) concentrations were measured by spectrophotometric technique, percentages of glycated hemoglobin (HbA1c) was estimated by a modified high-performance liquid chromatography. TAS was determined by a modified ferric reducing ability of plasma (FRAP) assay.

Results: The mean age of the total study subjects was $50 \pm 9$ years. Among them, $31 \%$ were male and $69 \%$ were female. Biguanides and sulfonylureas groups were matched for age, sex and glycemic status, but not matched for body mass index (BMI) and acute glycemic status (FPG and PPG). The mean value of TAS in subjects treated by Biguanides was $1386 \pm 249 \mu \mathrm{mol} / \mathrm{L}$ and in subjects treated with sulfonylureas it was $1278 \pm 275 \mu \mathrm{mol} / \mathrm{L}$. Except PPG in the Biguanides treated group, acute or chronic glycemic status showed no significant relationship with TAS. Univariate linear regression analysis showed a significant association of TAS with Biguanides monotherapy $(\beta=0.2039$, $p=0.042$ ) but it disappeared when adjusted for glycemic status, age, sex, BMI, duration of diabetes mellitus and drug use $(\beta=0.0455, p=0.6905)$.
\end{abstract}

Conclusion: It may be concluded that there is no difference between Biguanides and Sulfonylureas regarding their effects on total antioxidant capacity in type 2 diabetic subjects.

Keywords: Total antioxidant status; Total antioxidant capacity; FRAP; Type 2 DM; Biguanides; Sulfonylureas

\section{Introduction}

The prevalence of type 2 diabetes mellitus (DM) in Bangladesh has increased dramatically over the past two decades and continues to rise as a disease of immeasurable class [1]. Many researchers have been observing worldwide that antioxidants commonly are raised. As antioxidants are an assistant for our health, may delay the early onset of type $2 \mathrm{DM}$ by mopping up reactive oxygen species (ROS) that may play a protective role to prevent the early stages of type $2 \mathrm{DM}$ through enhancing insulin action. ROS are a byproduct in type $2 \mathrm{DM}$, generated during protein glycation and as a consequence of advanced glycation end products-receptor binding; they impair insulin signaling pathways and induce cytotoxicity in pancreatic $\beta$ (beta) cells [2]. Oxidative stress is now thought to be an important marker in the pathogenesis of type 2 $\mathrm{DM}$ and its complications through the impairment of pancreatic $\beta$-cells function [3].

Pharmacological therapy of type 2 diabetes has changed dramatically in the last 10 years, with new drugs and drug classes becoming available. These agents reduce hyperglycemia by decreasing hepatic gluconeogenesis (primary effect) and increasing peripheral insulin sensitivity (secondary effect). Biguanides is used as monotherapy or in combination with sulfonylureas as well as in combination with other antidiabetic drugs or with insulin. Sulfonylureas work by stimulating insulin release from the $\beta$ cells of the pancreas and may slightly improve insulin resistance in peripheral target tissues (muscle, fat cells). On average, this class reduces glycated hemoglobin $\mathrm{A}_{1 \mathrm{c}}\left(\mathrm{HbA}_{1 \mathrm{c}}\right)$ levels by
0.8-2.0 percent and fasting plasma glucose (FPG) concentrations by 3.3-3.9 $\mathrm{mmol} / \mathrm{L}$, with the greatest reductions observed in patients with the highest FPG concentrations at the initiation of therapy [4-6]. Whereas Biguanides (metformin) works by reducing hepatic glucose output and, to a lesser extent, enhancing insulin sensitivity in hepatic and peripheral tissues. Metformin has been shown to reduce $\mathrm{HbA}_{1 \mathrm{c}}$ levels by approximately 1.5-2.0 percent and FPG levels by 2.8-3.9 $\mathrm{mmol} / \mathrm{L}[4,5,7]$. Despite the agreement on the increase of free radicals in diabetic patients, the level of antioxidants in diabetic patients has been reported to decrease $[8,9]$ increase $[10,11]$ or stay the same [12]. The effect of diabetes on total antioxidant levels seems to be complicated by the effect of diabetes on individual antioxidant systems. Increased oxidative stress is a widely accepted participant in the development and progression of diabetes and its complications [13,14]. In light of the major role of oxidative stress in the development, progression and

*Corresponding author: Saiedullah M, Department of Physiology and Molecular Biology, Bangladesh University of Health Sciences (BUHS), Bangladesh, Tel: 8802-8055312, 9010654; Fax: 880-2-8055312; E-mail: md.saiedullah@gmail.com

Received: January 25, 2016; Accepted: April 25, 2016; Published: April 27, 2016

Citation: Siddique MAH, Begum A, Begum S, Khan MH, Saiedullah M, et al. (2016) Comparison of Antioxidative Effects of Biguanides and Sulfonylureas Monotherapy on Total Antioxidant Status in Newly-Diagnosed Patients with Type 2 Diabetes Mellitus. Diabetes Case Rep 1: 104. doi: 10.4172/2572-5629.1000104

Copyright: ( 2016 Siddique MAH, et al. This is an open-access article distributed under the terms of the Creative Commons Attribution License, which permits unrestricted use, distribution, and reproduction in any medium, provided the original author and source are credited. 
Citation: Siddique MAH, Begum A, Begum S, Khan MH, Saiedullah M, et al. (2016) Comparison of Antioxidative Effects of Biguanides and Sulfonylureas Monotherapy on Total Antioxidant Status in Newly-Diagnosed Patients with Type 2 Diabetes Mellitus. Diabetes Case Rep 1: 104. doi: $10.4172 / 2572-5629.1000104$

Page 2 of 5

complications of DM, antioxidants may serve as a potential therapy for combating the problems [15]. Thus the ideal therapy for DM would be a drug that not only possess antihyperglycemic effect, but which also enhances or protects the antioxidant defense systems.

Biguanides and sulfonylureas are the effective antihyperglycemic drugs for the management of type 2 DM. Some studies claimed that these drugs have antioxidant property $[16,17]$ while other claimed an opposite or no effect on oxidant/antioxidant balance [17,18]. Moreover, oxidative stress may partly be associated with eating habit, lifestyle and heredity. So the present study was designed to compare plasma total antioxidant status (TAS) between type 2 diabetic subjects treated with Biguanides monotherapy and Sulfonylurea monotherapy in a tertiary health care center.

\section{Materials and Methods}

\section{Study designs and subjects}

This cross-sectional observational study was carried out in the Department of Applied Laboratory Sciences, Bangladesh University of Health Sciences (BUHS) for a period of four months between MarchJune 2013. According to inclusion-exclusion criteria, one hundred (100) subjects with type 2 diabetes mellitus were included purposively: fifty (50) subjects received Biguanides (Metformin) monotherapy (500-1700 $\mathrm{mg} /$ day) as an oral hypoglycemic agent and 50 subjects received Sulfonylureas monotherapy (Glibenclamide, $2-5 \mathrm{mg} /$ day) as oral hypoglycemic agent for the management of DM during last six months or more. The subjects were included irrespective of race, religion and socioeconomic status. Subjects with serious comorbid diseases (infection, stroke, myocardial infarction, major surgery, malabsorption etc.), pregnant or lactating women, subjects with liver or kidney dysfunction, history of using drugs other than Biguanides or Sulfonylureas which significantly affect glucose metabolism (antihypoglycemic agents, glucocorticoids, oral contraceptives, thiazide diuretics etc.) or taking vitamin supplements were excluded. Verbal consent was taken before data collection, clinical examination and specimen collection. Clinical history, anthropometric data, duration of $\mathrm{DM}$, duration of drug use and type of oral antihyperglycemic agents were recorded from participant's information or hospital registry (Bangladesh Institute of Health Sciences \& Hospital, BIHSH, Dhaka).

\section{Anthropometric measurements}

Anthropometric indices included height and weight. All the individuals were measured wearing light clothing without shoes and hats. Height was measured to the nearest $0.1 \mathrm{~cm}$ using a portable stadiometer and weight was measured to the nearest $0.1 \mathrm{~kg}$ using calibrated platform scales.

\section{Clinical measurements}

Fasting venous blood was collected between $8.00-9.00 \mathrm{am}$. Venous blood $(5 \mathrm{ml})$ was taken by venipuncture with the subject sitting comfortably in a chair in a quiet room. A portion of blood specimen was poured into a test tube containing sodium fluoride to measure plasma glucose concentrations. Another portion of blood specimen was poured into another test tube containing Ethylene diamine tetra acetic acid (EDTA) to measure plasma antioxidant capacity. After 15 minutes blood samples were centrifuged for 10 minutes at 3000 rpm to obtain plasma. The EDTA treated plasma was preserved in capped microtubes at $-20^{\circ} \mathrm{C}$ until analysis. After 2 hours of breakfast, $2 \mathrm{~mL}$ blood was collected for the measurement of postprandial plasma glucose concentration.
Plasma glucose concentrations were determined by hexokinase method by the automated chemistry analyzer, Dimension RxL Max (Siem, USA). Glycated hemoglobin levels $\left(\% \mathrm{HbA}_{1}\right)$ were measured by a modified high-performance liquid chromatography using Variant ${ }^{\oplus}$ Turbo Hemoglobin $A_{1 c}$ Program (Bio-Rad Laboratories, Inc, USA). Plasma total antioxidant power/capacity was determined by a modified ferric reducing ability of plasma (FRAP) assay [19]. In brief, $240 \mathrm{ml}$ FRAP working reagent was prepared by mixing $200 \mathrm{ml}$ acetate buffer ( $\mathrm{pH} 3.6$ ), $20 \mathrm{ml}$ of $10 \mathrm{mM} \mathrm{2,4,6-tripyridyl-s-triazine} \mathrm{(TPTZ}$ MW 312.33, Sigma-Aldrich, Switzerland), dissolved in $40 \mathrm{mM} \mathrm{HCl}$ (Merck, Germany) solution and $20 \mathrm{ml}$ of $20 \mathrm{mM} \mathrm{FeCl}_{3} \cdot 6 \mathrm{H}_{2} \mathrm{O}$ (MW -270.32, Merck, Germany) solution. Standard solution for calibration was prepared by $\mathrm{FeSO}_{4} .7 \mathrm{H}_{2} \mathrm{O}$, (MW 278.02, Scharlau, Spain). The concentrations of standard solutions were $31.25,62.5,125,250,500$ and $1000 \mu \mathrm{M} \mathrm{FeSO}_{4} .7 \mathrm{H}_{2} \mathrm{O}$. Three hundred (300) $\mu \mathrm{L}$ freshly prepared FRAP working reagent was taken into each well of blank microplate. Then reagent blank was taken. Twenty microliter $(20 \mu \mathrm{L})$ water was added to the first two wells, $20 \mu \mathrm{L}$ of each $\mathrm{FeSO}_{4} .7 \mathrm{H}_{2} \mathrm{O}$ standard solution (31.25$1000 \mu \mathrm{mol} / \mathrm{L}$ ) was added serially in duplicated. Two times pre-diluted plasma specimens were added to the wells sequentially in duplicate. After 10 minutes of incubation, absorbance was taken at $620 \mathrm{~nm}$ using a microplate reader (Multiskan, Thermo Scientific). From the standard curve, FRAP (considered as Total Antioxidant Capacity, TAC) of each specimen was determined and the mean value of two reading multiplied by 2 (dilution factor) was used for statistical analysis.

\section{Statistical analysis}

Statistical analysis was performed using MedCalc ${ }^{\circ}$ version 11.4 for Windows. Data were expressed as Mean \pm SD (standard deviation) and/or percentage (\%) as appropriate. The statistical significance of differences between the values was assessed by the independent sample $t$ test or Fisher's exact test (as appropriate). A two-tailed $p$ value of $<0.05$ was considered statistically significant. Graphical presentations were done with GraphPad Prism version 5.04 for Windows (GraphPad Software, San Diego California USA)

\section{Results}

\section{Characteristics of the participants}

One hundred type 2 diabetic subjects were included to compare the antioxidant efficacy of Biguanides and Sulfonylureas. Of them 50 subjects used Biguanides monotherapy and the rest used Sulfonylureas monotherapy during the last 6 months for the management of DM. Of the total subjects 31 (31\%) were male and 69 (69\%) were female. The mean age of the study subjects was $50 \pm 9$ years. In the total subjects, the mean BMI was $26.6 \pm 3.9 \mathrm{~kg} / \mathrm{m}^{2}$, Waist-Hip ratio was $0.89 \pm 0.09$ and mid upper arm circumference was $29.9 \pm 2.6 \mathrm{~cm}$. Fifty four percent (54\%) of the study subjects had a BMI up to $27 \mathrm{~kg} / \mathrm{m}^{2}$ and $46 \%$ had BMI $>27 \mathrm{~kg} / \mathrm{m}^{2}$. Characteristics of the Biguanides treated subjects and Sulfonylureas treated subjects are presented in Table 1. Fifty percent (50\%) of the study subjects had hypertension and used anti-hypertensive medication for the management of hypertension. Among the participants, only $2 \%$ had a habit of smoking. There was no primary history of allergy, edema, severe illness, cancer, infection, liver dysfunction and chronic kidney disease (CKD) according to hospital's registry or participant's information.

The mean of fasting plasma glucose, post-prandial plasma glucose and $\mathrm{HbAlc}$ in the total study $(\mathrm{n}=100)$ were $5.9 \pm 1.3 \mathrm{mmol} / \mathrm{L}, 8.4 \pm$ $2.1 \mathrm{mmol} / \mathrm{L}$ and $6.7 \pm 0.6 \%$ respectively. The mean duration of DM from the first detection was $4.4 \pm 4.3$ years. Biguanides group and 
Citation: Siddique MAH, Begum A, Begum S, Khan MH, Saiedullah M, et al. (2016) Comparison of Antioxidative Effects of Biguanides and Sulfonylureas Monotherapy on Total Antioxidant Status in Newly-Diagnosed Patients with Type 2 Diabetes Mellitus. Diabetes Case Rep 1: 104. doi: $10.4172 / 2572-5629.1000104$

Page 3 of 5

\begin{tabular}{|c|c|c|c|}
\hline Variables & $\begin{array}{c}\text { Biguanides } \\
\text { group (n=50) }\end{array}$ & $\begin{array}{c}\text { Sulfonylureas } \\
\text { group }(\boldsymbol{n}=\mathbf{5 0})\end{array}$ & $\begin{array}{c}\text { Significance } \\
\text { of test (p) }\end{array}$ \\
\hline Age (yrs) & $50 \pm 8$ & $50 \pm 10$ & $0.8589^{\S}$ \\
\hline Sex (Male/Female) & $16(32 \%) / 34(68 \%)$ & $15(30 \%) / 35(70 \%)$ & $1.000^{*}$ \\
\hline Body mass index $\left(\mathrm{kg} / \mathrm{m}^{2}\right)$ & $27.9 \pm 4.0$ & $25.3 \pm 3.3$ & $0.001^{\S}$ \\
\hline Waist-Hip ratio & $0.88 \pm 0.12$ & $0.89 \pm 0.04$ & $0.577^{\S}$ \\
\hline $\begin{array}{c}\text { Mid upper arm } \\
\text { circumference (cm) }\end{array}$ & $30.4 \pm 2.6$ & $29.5 \pm 2.6$ & $0.098^{\S}$ \\
\hline Hypertension (yes/no) & $29(58 \%) / 21(42 \%)$ & $21(42 \%) / 29(58 \%)$ & $0.1612^{*}$ \\
\hline $\begin{array}{c}\text { Fasting plasma glucose } \\
\text { (mmol/L) }\end{array}$ & $5.5 \pm 1.3$ & $6.2 \pm 1.2$ & $0.007^{\S}$ \\
\hline $\begin{array}{c}\text { Postprandial plasma } \\
\text { glucose (mmol/L) }\end{array}$ & $7.7 \pm 1.9$ & $9.0 \pm 2.2$ & $0.002^{\S}$ \\
\hline $\begin{array}{c}\text { HbA } 1 \text { ( } \%) \\
\text { Duration of DM (from 1st } \\
\text { detection: yrs) }\end{array}$ & $6.7 \pm 0.5$ & $6.8 \pm 0.6$ & $0.220^{\S}$ \\
\hline \$, Independent sample t test; ${ }^{*}$, Fisher's exact test. & $5.5 \pm 4.9$ & $0.011^{\S}$ \\
\hline
\end{tabular}

Table 1: Characteristics of the Biguanides and Sulfonylureas group.

Sulfonylureas groups were matched for age $(p=0.8589)$, sex $(p=1.00)$, chronic glycemic status $(p=0.220)$ and hypertension $(\mathrm{p}=0.1612)$ but not matched for BMI, acute glycemic status (FPG and PPG, $p<0.01$ ) and duration of DM $(p=0.011)$ (Table 1$)$.

\section{Total antioxidant status}

The mean value of TAS in the total study subjects $(n=100)$ was 1332 $\pm 266 \mu \mathrm{mol} / \mathrm{L}$. The mean value of TAS in Biguanides treated subject was $1386 \pm 249 \mu \mathrm{mol} / \mathrm{L}$ and in Sulfonylureas treated subjects it was $1278 \pm 275 \mu \mathrm{mol} / \mathrm{L}$. Figure 1 shows the comparison of TAS between Biguanides treated and Sulfonylureas treated subjects. Two-tailed unpaired $t$ test showed that the $t$ value of the comparison was 2.062 . The difference between the means was $108 \pm 52 \mu \mathrm{mol} / \mathrm{L}(p=0.042)$.

\section{Association of TAS with biguanides and sulfonylureas}

The Pearson correlation coefficient of TAS with anthropometric, clinical parameters and glycemic status in subjects treated with Biguanides and Sulfonylureas is presented in (Table 2). Except age and PPG, no parameters showed significant correlation with TAS. Linear regression analysis considering TAS as an outcome variable and Biguanides-sulfonylureas groups as independent variable showed a significant positive association of TAS with Biguanides monotherapy $(\beta=0.2039, p=0.042)$ but it disappeared when adjusted for acute/ chronic glycemic status, age, sex, BMI, duration of DM, and duration of drug used (Table 3).

\section{Discussion}

The global health burden is increasing due to the upward trend in the incidence of non-communicable diseases (NCDs) of which $\mathrm{DM}$ are a major component. Oxidative stress may play a major role in the development and progression of short-term and long-term complications of DM. For the management of DM, several approaches are taken to achieve glycemic goal. The pharmacological agents, i.e., Biguanides, Sulfonylureas, Thiazolidinediones, a-glycosidase inhibitors are frequently used for the management of DM due to potential benefit on glycemic status.

In this study, a significantly increased plasma TAS was observed in type 2 diabetic subjects treated with Biguanides compared to those treated with Sulfonylureas $(p=0.042)$. This finding is consistent with findings of Abdulkadir et al. [17] who reported a significant rise in total antioxidant status (TAS) after a 2 months Biguanides monotherapy compared to Sulfonylurea monotherapy [17]. Faure et al. [20] also reported a significant increase in antioxidant protection as evidenced by increased TAS in type 2 diabetic subjects receiving Biguanides monotherapy [20]. Tessier et al. [21] observed a significant rise in serum Vitamin E level after a 24-week Biguanide monotherapy [21]. This may be due to increase in endogenous antioxidants $(\mathrm{Cu}-$, $\mathrm{Zn}$ - superoxide dismutase, catalase and glutathione reductase levels) $[22,23]$ or exogenous antioxidants [22] in type 2 diabetic subjects treated with Biguanides. In this study, two groups were matched for age, sex, waist-hip ratio, blood pressure and chronic glycemic status (HbA1c). However, acute glycemic status i.e., fasting plasma glucose $(\mathrm{p}=0.007)$ and postprandial plasma glucose levels $(\mathrm{p}=0.002)$; duration of DM ( $\mathrm{p}=0.011)$ were not matched between Biguanides treated subjects and Sulfonylureas treated subjects. So the difference in TAS between Biguanides and Sulfonylurea treated was apparent. Plasma TAS also differed significantly between males and females $(\mathrm{p}=0.016)$. But fasting plasma glucose $(\mathrm{p}=0.004)$, BMI $(\mathrm{p}=0.009)$, duration of $\mathrm{DM}(\mathrm{p}=0.035)$ and duration of drug use $(\mathrm{p}=0.004)$ differs significantly

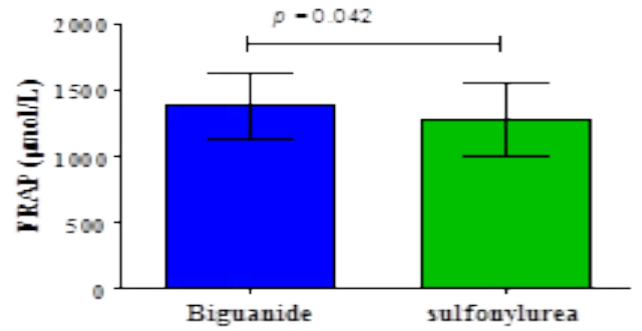

Figure 1: Comparison of TAS between Biguanides treated and Sulfonylureas treated subjects.

\begin{tabular}{|c|c|c|c|c|}
\hline \multirow{2}{*}{$\begin{array}{c}\text { TAS vs } \\
\text { Variables }\end{array}$} & \multicolumn{2}{|c|}{ Biguanides group $(n=50)$} & \multicolumn{2}{|c|}{ Sulfonylureas group $(n=50)$} \\
\hline & $\begin{array}{c}\text { Correlation } \\
\text { coefficient }(r)^{*}\end{array}$ & $p$ value & $\begin{array}{l}\text { Correlation } \\
\text { coefficient }(r)^{*}\end{array}$ & $p$ value \\
\hline Age & 0.3299 & 0.0193 & 0.2797 & 0.0492 \\
\hline BMI & 0.1181 & 0.4139 & 0.1141 & 0.4302 \\
\hline WHR & -0.1499 & 0.2989 & 0.1571 & 0.2759 \\
\hline MUAC & -0.0444 & 0.7595 & -0.0203 & 0.8886 \\
\hline FPG & -0.1423 & 0.3241 & 0.0893 & 0.5373 \\
\hline PPG & -0.3297 & 0.0194 & 0.1173 & 0.4171 \\
\hline $\mathrm{HbA}_{1 \mathrm{c}}$ & -0.1931 & 0.1791 & -0.1133 & 0.4335 \\
\hline Duration of DM & 0.0732 & 0.6134 & 0.0278 & 0.8482 \\
\hline $\begin{array}{l}\text { Duration of } \\
\text { drug use }\end{array}$ & 0.1163 & 0.4212 & 0.2301 & 0.1080 \\
\hline
\end{tabular}

*Pearson correlation analysis; BMI, Body mass index; WHR, Waist-hip ratio MUAC, Mid upper arm circumference; FPG, fasting plasma glucose; PPG Postprandial plasma glucose; HbA1c, Glycated hemoglobin; DM, Diabetes mellitus.

Table 2: Relationship of TAS with different variables.

\begin{tabular}{|c|c|c|}
\hline Parameters & $\boldsymbol{\beta}$ value & p value \\
\hline Group (Biguanides) & 0.0455 & 0.6905 \\
\hline Age & 0.2687 & 0.0094 \\
\hline Sex (Female) & -0.2611 & 0.0164 \\
\hline FPG & -0.0546 & 0.6691 \\
\hline PPG & -0.1019 & 0.4020 \\
\hline HbA ${ }_{1 c}$ & -0.1201 & 0.2486 \\
\hline BMl & 0.1833 & 0.0888 \\
\hline Duration of DM & -0.1026 & 0.3764 \\
\hline Duration of Medication & -0.0723 & 0.5294 \\
\hline
\end{tabular}

Table 3: Multiple linear regression analysis with TAS as outcome variable. 
Citation: Siddique MAH, Begum A, Begum S, Khan MH, Saiedullah M, et al. (2016) Comparison of Antioxidative Effects of Biguanides and Sulfonylureas Monotherapy on Total Antioxidant Status in Newly-Diagnosed Patients with Type 2 Diabetes Mellitus. Diabetes Case Rep 1: 104. doi: $10.4172 / 2572-5629.1000104$

Page 4 of 5

between males and females. On the other hand, postprandial plasma glucose $(\mathrm{p}=0.189), \mathrm{HbA}_{1 \mathrm{c}}(\mathrm{p}=0.831)$ and age $(\mathrm{p}=0.1639)$ showed no significant difference between males and females. Thus the difference in TAS between males and females may be linked to the levels of fasting plasma glucose, BMI, duration of DM and duration of drug use.

On Pearson's correlation analysis, no other parameters except age showed a significant relationship with TAS. Finally, multiple linear regression analysis showed a significant positive association of Biguanides with TAS, but when adjusted for age, sex, BMI, acute or chronic glycemic status $\left(\mathrm{HbA}_{1 c}\right)$, duration of $\mathrm{DM}$ and duration of drug use the association of TAS with Biguanides disappeared. So the apparent difference in TAS in subjects treated with Biguanides and in subjects treated with Sulfonylureas was not associated with these antihyperglycemic monotherapy i.e., there was no difference between Biguanides and Sulfonylureas regarding their effects on total antioxidant status. Conflicting data regarding the effects of Biguanides and sulfonylureas on oxidative stress in type 2 diabetic subjects were reported. Yilmaz et al. [24] and Chugh et al. [25] found an insignificant increase in TAS levels in type 2 diabetic subjects treated with Sulfonylureas (Glibenclamide) [24,25] whereas Jennings et al. [26] found no significant change in endogenous antioxidant activity in type 2 diabetic subjects treated with Sulfonylureas (Glibenclamide) [26]. Thus the reported difference between the two agents may be linked to the confounding effects of age and sex.

There are several evidences that hyperglycemia enhances oxidative stress. Among these autoxidation of glucose [27], activation of the polyol pathway $[28,29]$ is critically important. Since Biguanides or Sulfonylureas are effective antihyperglycemic agents, a decreased glucose autoxidation and deactivation of the polyol pathway may drastically improve the antioxidants by controlling blood glucose levels and this fact support our results as Biguanides group and Sulfonylureas group were matched for chronic glycemic status.

Again, in this study, TAS in type 2 diabetic subjects treated with Biguanides $(309 \mu \mathrm{mol} / \mathrm{L}, \mathrm{p}<0.0001)$ or Sulfonylureas $(201 \mu \mathrm{mol} / \mathrm{L}$, $\mathrm{p}<0.0001)$ are significantly higher compared to that found for newly diagnosed never treated type 2 diabetic subjects in another recent study carried out by the same research group [30]. Further, TAS values are much closer to that of nondiabetic controls (TAS was only $39 \mu \mathrm{mol} / \mathrm{L}$ lower for Biguanides, $\mathrm{p}=0.4855$ and $147 \mu \mathrm{mol} / \mathrm{L}$ lower for Sulfonylureas, $\mathrm{p}=0.012$ ) of the mentioned study [30]. Thus, both Biguanides and Sulfonylureas monotherapy are may partly be associated with the improvement of plasma antioxidant capacity having similar potency against oxidative stress.

Limitations of the study: The major limitation of this study includes cross-sectional design with small sample size, lack of follow up, lack of other confounding variables like eating habit, lifestyle and physical activity. Intense prospective studies including other confounding factors are required to be done in a Bangladeshi population to clarify the issues further.

\section{Conclusion}

Plasma antioxidant status is apparently higher in type 2 diabetic subjects treated with Biguanides compared to those treated with Sulfonylureas and there is no difference between Biguanides and Sulfonylureas regarding their effects on total antioxidant status in type 2 diabetic subjects.

\section{References}

1. IDF diabetes atlas (2012) International Diabetes Federation (6thedn). Country estimates table 2011

2. Akbar S, Bellary S, Griffiths HR (2011) Dietary antioxidant interventions in type 2 diabetes patients: a meta-analysis. British Journal of Diabetes \& Vascular Disease 11: 62-68.

3. Chang $Y$, Chuang $L(2010)$ The role of oxidative stress in the pathogenesis of type 2 diabetes: from molecular mechanism to clinical implication. Am J Transl Res 2: 316-331.

4. DeFronzo RA (1999) Pharmacologic therapy for type 2 diabetes mellitus. Ann Intern Med 1999; 131:281-303.

5. Feinglos MN, Bethel MA (1998) Treatment of type 2 diabetes mellitus. Med Clin North Am 82: 757-790

6. Luna B, Hughes AT, Feinglos MN (1999) The use of insulin secretagogues in the treatment of type 2 diabetes. Prim Care 26: 895-915.

7. DeFronzo RA, Goodman AM (1995) Efficacy of metformin in patients with noninsulin-dependent diabetes mellitus. The Multicenter Metformin Study Group. N Engl J Med 333: 541-549.

8. Opara EC, Rahman EA, Soliman S, Kamel WA, Souka S, et al. (1999) Depletion of total antioxidant capacity in type 2 diabetes. Metabolism 48: 1414-1417.

9. Song F, Jia W, Yao Y, Hu Y, Lei L, et al. (2007) Oxidative stress, antioxidant status and DNA damage in patients with impaired glucose regulation and newly diagnosed type 2 diabetes. Clin Sci (Lond) 112: 599-606.

10. Srivatsan R, Das S, Gadde R, Manoj-Kumar K, Taduri S, et al. (2009) Antioxidants and lipid peroxidation status in diabetic patients with and without complications. Arch Iran Med 12: 121-127.

11. Dominguez C, Ruiz E, Gussinye M, Carrascosa A (1998) Oxidative stress at onset and in early stages of type 1 diabetes in children and adolescents. Diabetes Care 21: 1736-1742.

12. Giugliano D, Ceriello A, Paolisso G (1996) Oxidative stress and diabetic vascular complications. Diabetes Care 19: 257-267.

13. Baynes JW, Thorpe SR (1999) Role of oxidative stress in diabetic complications: A new perspective on an old paradigm. Diabetes 48: 1-9.

14. Ceriello A (2000) Oxidative stress and glycemic regulation. Metabolism 49: 27 29.

15. Maritim, Sanders RA, Watkins JB (2003) Diabetes, oxidative stress, and antioxidants: A review. J Biochem Mol Toxicol 17: 24-38.

16. Faure $P$, Rossini E, Wiernsperger N (1999) An insulin sensitizer improves the free radical defense system potential and insulin sensitivity in high fructose-fed rats. Diabetes 48: 353-357.

17. Abdulkadir, Thanoon IA (2012) Comparative Effects of Glibenclamide and Metformin on C-Reactive Protein and Oxidant/Antioxidant Status in Patients with Type II Diabetes Mellitus. Sultan Qaboos Univ Med J 12: 55-61.

18. Signorini AM, Fondelli C, Renzoni E, Puccetti C, Gragnoli G, et al. (2002) Antioxidant effects of glicazide, glibenclamide, and metformin in patients with type 2 diabetes mellitus. Curr Ther Res Clin Exp 63: 411-420.

19. Benzie IFF, Strain JJ (1996) The ferric reducing ability of plasma (FRAP) as a measure of "antioxidant power": the FRAP assay. Anal Biochem 9: 70-76.

20. Faure $P$, Wiernsperger N, Polge C, Favier A, Halimi S (2008) Impairment of the antioxidant properties of serum albumin in patients with diabetes: protective effects of metformin. Clin Sci (Lond) 114: 251-256.

21. Tessier D, Maheux P, Khalil A, Fülöp T (1999) Effects of gliclazide versus metformin on the clinical profile and lipid peroxidation markers in type 2 diabetes. Metabolism 48: 897-903.

22. Pavlović D, Kocić R, Kocić G, Jevtović T, Radenković S, et al. (2000) Effect of four week metformin Treatment on plasma and erythrocyte antioxidative defense enzymes in newly diagnosed obese patients with type 2 diabetes. Diabetes Obes Metab 2: 251-256.

23. Skrha J, Prazny M, Hilgertova J, Kvasnicka J, Kalousova M, et al. (2007) Oxidative stress and endothelium influenced by metformin in type 2 diabetes mellitus. Eur J Clin Pharmacol 63: 1107-1114.

24. Yilmaz M, Bukan N, Ayvaz G, Karakoç A, Törüner F, et al. (2005) The effects of 
Citation: Siddique MAH, Begum A, Begum S, Khan MH, Saiedullah M, et al. (2016) Comparison of Antioxidative Effects of Biguanides and Sulfonylureas Monotherapy on Total Antioxidant Status in Newly-Diagnosed Patients with Type 2 Diabetes Mellitus. Diabetes Case Rep 1 : 104. doi: $10.4172 / 2572-5629.1000104$

Page 5 of 5

rosiglitazone and metformin on oxidative stress and homocystine levels in lean patients with polycystic ovary syndrome. Hum Reprod 20: 3333-3340.

25. Chugh SN, Dhawan R, Kishore K, Sharma A, Chugh K (2001) Glibenclamide vs gliclazide in reducing oxidative stress in patients of non-insulin dependent diabetes mellitus. A double blind randomized study. J Assoc Physicians India 49: 803-807.

26. Jennings PE, Scott NA, Saniabadi AR, Belch JJ (1992) Effects of gliclazide on platreactivity and free radicals in type 2 diabetic patients: Clinical assessment. Metabolism 4136-4139.

27. Brownlee M (2005) The pathobiology of diabetic complications: a unifying mechanism. Diabetes 54: 1615-1625.

28. Soliman GZA (2008) Blood lipid peroxidation (superoxide dismutase malondialdohyde, glutatione) level in Egyptian type 2 diabetic patients Singapore Med J 49: 129-136.

29. Reaven G (1996) Insulin resistance and its consequences: type 2 diabetes mellitus and coronary heart disease. Diabetes mellitus: a fundamental and clinical text Philadelphia. Circulation 93: 1780-1783.

30. Siddique MAH, Tamannaa Z, Kamaluddin SM, Saiedullah M, Khan MAH, et al (2016) Total antioxidant status in newly-diagnosed type II diabetes patients in Bangladeshi population. J Mol Pathophysiol 5: 5-9. 